\title{
El árbol de Bruno Munari ${ }^{1}$
}

\author{
Peppe Cirotti y Xenia Pacheco
}

\section{I. Árbol y ensayos pedagógicos: la metáfora}

Desde el fondo blanco de la página de un libro, un árbol pequeño confiaba toda su fuerza al sinuoso lenguaje de su despeinada melena. Hacía rato que buscábamos, Ana Rodríguez, Nuria Corrales, Peppe Cirotti y yo, una figura, un signo, cuando menos un guiño, que desde alguno de esos libros sobre diseño que ojeábamos, recogiera y sintetizara las ideas y deseos sobre las que se funda la serie Ensayos Pedagógicos, para que fuera el logo que identificara nuestro trabajo editorial. Observábamos las formas, comentábamos

1. Este artículo ensaya una respuesta y una explicación a los puntos de vista expresados por la señora rectora Sonia Marta Mora Escalante de la Universidad Nacional, en la presentación del primer número de Ensayos Pedagógicos y de su número especial Territorio distante el encuentro entre la gente y la naturaleza, a propósito de la orientación editorial y la organización de los textos en dicho número. Se hace mediante una metáfora que relaciona lo anterior con el árbol de Murani, elegido como logo de la serie. 
los dibujos, en perenne pesquisa, hasta que el árbol diseñado por el artista y pedagogo italiano Bruno Munari, logró detener nuestras miradas para demostramos que contenía, en su expresión, la representación de tales ideas y deseos. La decisión fue espontánea y unánime, ese árbol era lo que buscábamos.

Lo que más nos llamaba la atención, era la constitución de las ramas de su copa porque transmitían una curiosa sensación de flexibilidad, pues se inclinaban y doblaban en direcciones diversas, imprimiéndole distintos grados de tensión al ramaje. Como en un juego, dicha tensión, así como la orientación y los movimientos de las ramas, conformaban un todo armónico que simultáneamente las comunicaba, desunía y volvía a convocar. Suspendida en direcciones que unas veces le parecían propias y hasta antagónicas, el conjunto de la copa aparecía sujeto por un tronco separado en varias pequeñas vertientes, $y$, aunque éste era el punto de apoyo de la enramada y señalaba una centralidad que lo anclaba a la tierra, el tronco discreto, cumplía su función sin robar importancia a las ramas que se dispersaban en el aire, como buscando su propio camino, autónomamente. Ni el tamaño, ni la dirección, ni la forma de las ramas constituían señales para la discriminación: el tronco era el apoyo y la vinculación de todas y éste, aunque nutrición y sostén, ni las poseía ni se reflejaba en ellas.

Es sabido que, en general, la extensión de la copa de un árbol es proporcional a su raigambre, así que podíamos suponer que en este caso, bien podrían sopiar vientos fuertes, nuestro árbol, creación del maestro Munari, estaría seguro y firme.

Todos los elementos del dibujo descritos hasta aquí sirvieron de base a la metáfora entre éste y el trabajo que hacemos, conjuntamente con quienes escriben para Ensayos 
Pedagógicos. Así, las ramas constituyen las ideas que encuentran forma y concreción mediante el ensayo, modalidad que facilita la expresión de la naturaleza particular de aquéllas y la reflexión sobre temas que se escriben libremente, como los propios pensamientos que las originan, a partir de la£ vivencias, el estudio, los diálogos y discusiones, la búsqueda de respuestas, etc., que constituyen su base empírica - ¿Quién dice, por ejemplo, que el conocimiento tiene una única vía por donde transitar, un solo lenguaje para expresarse, un solo color, un solo tono? ¿Quién dice que las ideas nacen y discurren ordenadas, de acuerdo con cánones establecidos, sin mezclarse, traslaparse o contradecirse? ¿No puede, entonces, un físico comprender y escribir sobre literatura o un economista sobre arte? $¿ \mathrm{O}$ es que acaso está vedada la posibilidad para que una ama de casa reflexione sobre el déficit fiscal y aporte su explicación sobre ese tema?. La propia naturaleza con su biodiversidad y la cultura con su plasticidad, son una muestra de que la variedad y la complejidad son los patrones que subyacen a los órdenes que se han creado, los cuales muchas veces, en su afán por categorizar y clasificar, dividir y atomizar la realidad y el conocimiento, los niegan y desnaturalizan.

No se trata, sin embargo, de afirmar una dispersión de ideas, sin una intención común que congregue la diversidad de los pensamientos. Y es aquí donde el tronco del árbol y sus raíces participan de la metáfora que hemos descrito, puesto que es justamente la intención de dar lugar a la diversidad de pensamientos e ideas, la que se asimila a dichas partes del árbol y cierra o concluye la comparación entre éste y Ensayos Pedagógicos.

\section{II. Árbol y conocimiento: caer en la tentación}

Los árboles siempre han sido parte importante en las cosmogonías de muchos pueblos, de distintas culturas, tanto 
orientales como occidentales y han estado asociados con la vida y la muerte, con dioses y demonios. Para comunicarse con ellos, los seres humanos han bebido su savia, inhalado el aroma de sus maderas y flores, adornado sus cuerpos con ellos y los han preparado con sus resinas para sanarlos, protegerlos y hasta para amortajarlos. El triunfo y la paz, por su parte, también hallaron desde antiguo su representación en dos árboles: el laurel y el olivo.

Un brevísimo repaso nos permitirá asomarnos apenas a la historia de algunos árboles famosos, que fueron elegidos por importantes culturas como uno de sus símbolos. Podríamos empezar con el copal, de los mayas y aztecas, o el toromiro de los pascuenses, pasando por el de dos pueblos mapuches, el canelo y la hermosa araucaria. Incluyamos también al conocido árbol de la vida de los antiguos egipcios, habitado por cinco pájaros, cuatro de los cuales, orientados hacia el este, simbolizan las etapas de la juventud y la madurez, mientras que la vejez, también hecha pájaro, se posa en una de las ramas mirando hacia el ocaso. Así, en la alegoría egipcia, el sol une las vidas de árboles y humanos y señala su camino entre el nacimiento y la muerte.

Conquistadores y sabios también han estado relacionados con árboles, como aquél del famoso Hernán Cortés, bajo cuya sombra éste lloró, en una noche triste, cuando perdió una batalla por la toma de Tenochtitlan y fue también un árbol, de exuberante y colorida floración, el que dio cobijo y sombra al descanso de Buda. Uno de los símbolos más importantes de la tradición cristiana, la cruz, también proviene de un árbol y asimismo fue el fruto de uno de ellos, el del conocimiento, en el jardín del edén, el que tentara a Eva, quien en un acto que para algunos constituye alabada curiosidad científica, autonomía de criterio, puro aprendizaje por descubrimiento y para otros es tan solo insolente desobediencia, tomó el fruto y lo probó, por lo que perdió, para unos, la inocencia y para otros, la ignorancia. 
¿Cuál es entonces, el encantamiento que nos provocan los árboles? Tal vez sea que, con sus amplias copas, o sus altos troncos, se nos antojan a los humanos antenas hacia las regiones celestiales, mediante las cuales nos comunicamos con sus habitantes o bien porque con sus profundas raíces, escrutan los insondables abismos de las regiones oscuras, que nos parecen impenetrables e ignotas. $\mathrm{O}$ tal vez el hechizo arbóreo provenga de la contradictoria sensación que nos provocan, de volar hacia las alturas sin perder la seguridad del anclaje terrestre.

En fin, sea cual fuere el origen o la explicación del embrujo que producen los árboles, lo cierto es que, como versiones contemporáneas de Adanes y Evas, nos dejamos seducir por el árbol de Munari y caímos en la tentación de colaborar en la apertura de espacios que, a manera de frutos, den cabida a la exposición de las más diversas ideas, con todos los esfuerzos y dificultades que esto acarrea, los cuales interpretamos como señales que advierten sobre la pérdida de tranquilos paraísos. Así es que, como se ha visto, no podría haber sido sino un árbol, el icono que representara tales afanes.

\section{Munari maestro del conocimiento: los encuentros y los diálogos}

La fuerza que nos transmite el dibujo del árbol al que nos hemos referido, cuya delicada sencillez nos sugería ideas como las expuestas hasta aquí, sobre versatilidad, complejidad, energía, totalidad, contradicción, armonía, entre otras, fue creado por el artista y pedagogo italiano Bruno Munari (1907-1998), cuya preocupación por la enseñanza del arte, le llevó a plantear sus ideas de manera no sólo magistral e innovadora, sino además, comprometida con el desarrollo y la potenciación de los seres humanos. ¿Y qué mejor manera de 
conocer a un maestro sino mediante uno de sus discípulos? Bien se dice que a los árboles, como a los maestros, por sus frutos los conoceremos. Dejemos entonces que sea Peppe Cirotti, uno de ellos, quien a continuación nos relate cómo fue su encuentro con Munari, y compartamos con él la profunda y misteriosa alegría que nos dejan en el alma, para siempre, los maestros y los árboles.

Conocí a Bruno Munari y no imaginé que seguiría considerándolo un Maestro, con tanto afecto, por toda mi vida. Yo era estudiante de Bellas Artes y durante un festival entré en contacto con unas proyecciones, que despertaron en mis ojos el asombro de la transcoloración. Ver un color cambiarse "desde adentro", hasta transformarse en otro totalmente diferente, era, en aquella época sin computadoras, un evento que solo raramente se observaba en la naturaleza. Deseé inmediatamente aprender a hacer esas hermosuras, pero nadie, allí, supo explicármelas. La vasta investigación que hice luego no me condujo a ninguna parte y la única débil pista que tenía sobre la transcoloración, era una foto en el libro Codice ovvio de Bruno Munari, con una escueta leyenda que decía proyecciones a luz polarizada, 1952 . Como mis propias conjeturas y análisis no eran suficientes para resolver el enigma, en ocasión de un viaje a Milán, resolví hacerme el descarado y llamar al número que en la guía telefónica, decía pertenecer a Bruno Munari.

Él mismo respondió; yo le conté mi deseo de aprender la técnica que él conocía, para lo que le propuse acudir a su estudio para que ahí me la enseñara, a lo que repuso que no hacía falta que me incomodara porque ..." es sencillisimo, es como un emparedado: los filtros polarizados son el pan y la imagen es el jamón. Más bien, cuando tenga hecho algo, venga a visitarme para mostrármelo". Me quedé como tonto, pero de regreso a mi estudio intenté realizar lo que me había dicho ... y funcionaba. Me dediqué un año 
entero a investigar la técnica pero como todo alumno ingrato, no volví donde el maestro a mostrarle mis adelantos. No obstante, varios años después la vida me volvió a poner en Milán y sentí que ya era tiempo de pagar mi deuda con el Maestro. Le llamé por teléfono con vergüenza, creyendo que ya él se habría olvidado, pero él recordaba y esperaba. ¡Claro que lo recuerdo, venga, venga a mostrarmelo!, fueron sus palabras.

Frente al portón de su casa me sentí muy confundido, porque había muchos timbres y ninguno decía Munari. Solo uno de ellos mostraba, orgulloso, un cuadrito rojo en lugar del nombre. Llamé y al minuto me abrió la puerta un señor mayor, pequeñito, con el pelo blanco y los ojos centelleantes. Me miró sonriendo y lo primero que dijo fue « ¡la señal funcionó!". Ya en su estudio, me dispuse a compartir con él mis aprendizajes en relación con la transcoloración, de acuerdo con sus indicaciones y mis descubrimientos, pero a pesar de mis esfuerzos, las imágenes no se revelaban. ¿Por qué ocurría esto?, ¿por qué?. Finalmente, después de un rato de búsquedas infructuosas, comprendimos que había diferencias técnicas entre sus explicaciones y las aplicaciones que yo hacía de ellas. Toda la situación se fue tornando lúdica; el clima que nos envolvía era de diversión y juego. Como dos niños, compartíamos el gozo por aprender, y saboreábamos juntos el placer por la indagación, la experimentación, la construcción de las respuestas: ...tome , corte, ponga... y al final, ahí estaban mis proyecciones y él las disfrutaba tanto como yo.

Gocé en aquellos momentos de la presencia de un hombre que lograba ser feliz y contagiarme de su asombro conforme se maravillaba con el descubrimiento del mundo.

Después me mostró sus cosas, entre las que más disfrutaba estaban unas pinturas de aceite -olio- sobre tela, por ejemplo, aceite de oliva sobre un delantal, aceite mineral 
sobre un traje de mecánico y así sucesivas combinaciones llenas de ingenio y belleza que un gran artista puede imaginar para burlar a los críticos.

$\mathrm{El}$ arte de Bruno Munari siempre ha estado lejos del arte formal, serio y aburrido. Por ejemplo, sus máquinas inútiles de 1933 no eran, como las de Calder, en metal pesado, artístico. Eran en humilde cartulina, simples y livianas, desechables, como sus plegables esculturas para viajes, de 1958, que fueron consideradas por los críticos como "los jueguitos de Munari".

La capacidad de Munari para identificar lo obvio, lo cotidiano y despegarse de él, utilizando todos los estímulos que la realidad ofrece, era una característica de su fantasía. Ya se tratara de juntar palabras, colores, formas o conceptos, siempre llegaba a ver, con sus ojos de niño, castillos donde los otros veían piedras, bosques donde otros solo veían rayas. La dinámica propia de la creación la invención, lo estimuló a crear, jugando con su hijo, un museo imaginario con reconstrucciones teóricas de objeto fantásticos sobre la base de fragmentos de residuos con un método de indagación azaroso sobre formas, materias y estructuras. Una parte muy importante de su actividad artística fue con y para los niños enseñándoles directamente en escuelas primarias, los secretos de las estructuras y los caminos para entenderlos así como también produciendo objetos que estuvieran a la altura de la desbordante y crítica inteligencia infantil. Así, también la serie de los "Libros" de los años 70, para niños que no saben leer, la construye con materiales diversos como madera, corcho, paño y pluma, cartón y plástico y mediante estimulaciones táctiles y visuales, puso al alcance de pequeños iletrados su primer libro e hizo de esta experiencia, algo memorable. También para niños es su "Habitáculo" de 1971, una estructura pensada con la libertad del artista y la rigurosidad del diseñador, para estudiar, 
dormir, leer, meditar, escribir, escuchar música, conversar con los amigos, para los niños de una sociedad urbana, pobre en espacio, donde lo bello tiene cabida cuando también es útil.

Munari rechazó en toda su obra el concepto de libertad si esta sólo esconde ignorancia profunda. Desarrolló su método operativo, en el que la creatividad convive al lado de la ciencia y la tecnología. Los grandes artistas saben que el arte vive fuera de los museos y que cuando el sabio apunta a la luna, sólo los estúpidos miran el dedo. 